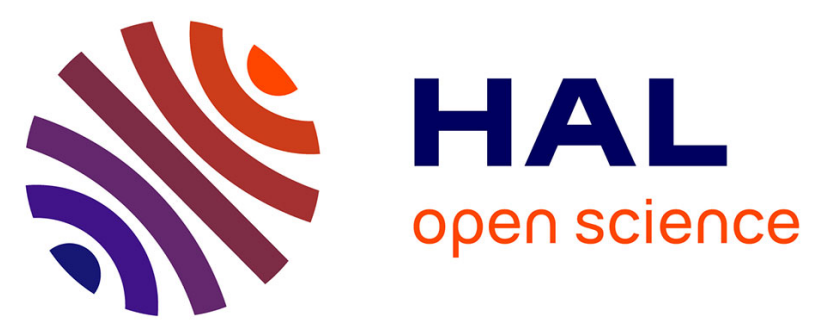

\title{
Irrigation scheduling of a classical gravity network based on the Covariance Matrix Adaptation - Evolutionary Strategy algorithm
}

S. Belaqziz, Sylvain Mangiarotti, Maël Le Page, S. Khabba, S. Er-Raki, T. Agouti, Laurent Drapeau, M. H. Kharrou, M. El Adnani, Lionel Jarlan

\section{To cite this version:}

S. Belaqziz, Sylvain Mangiarotti, Maël Le Page, S. Khabba, S. Er-Raki, et al.. Irrigation scheduling of a classical gravity network based on the Covariance Matrix Adaptation - Evolutionary Strategy algorithm. Computers and Electronics in Agriculture, 2014, 102, pp.64-72. 10.1016/j.compag.2014.01.006 . ird-01063086

\section{HAL Id: ird-01063086 \\ https://hal.ird.fr/ird-01063086}

Submitted on 11 Sep 2014

HAL is a multi-disciplinary open access archive for the deposit and dissemination of scientific research documents, whether they are published or not. The documents may come from teaching and research institutions in France or abroad, or from public or private research centers.
L'archive ouverte pluridisciplinaire HAL, est destinée au dépôt et à la diffusion de documents scientifiques de niveau recherche, publiés ou non, émanant des établissements d'enseignement et de recherche français ou étrangers, des laboratoires publics ou privés. 


\title{
Irrigation scheduling of a classical gravity network based on the Covariance Matrix Adaptation - Evolutionary Strategy algorithm
}

\author{
S. Belaqziz ${ }^{\text {a,c* }}$, S. Mangiarotti ${ }^{\text {b }}$, M. Le Page ${ }^{\text {b }}$, S. Khabba $^{\text {c }}$, S. Er-Raki ${ }^{\text {d }}$, T. Agouti ${ }^{\text {e }}$, L. \\ Drapeau $^{\text {b }}$, M.H. Kharrou ${ }^{\mathrm{f}}$, M. El Adnani ${ }^{\mathrm{a}}$, L. Jarlan ${ }^{\mathrm{b}}$ \\ ${ }^{a}$ LISI, Département d'Informatique, Faculté des Sciences Semlalia, Boulevard Prince My Abdellah, \\ Marrakech 40000, Morocco \\ ${ }^{b}$ CESBIO, Centre d'Etudes Spatiales de la BIOsphère, 18 Avenue Edouard Belin, 31401 cedex 9 , \\ Toulouse, France \\ ${ }^{c}$ LMME, Département de Physique, Faculté des Sciences Semlalia, Boulevard Prince My Abdellah, \\ Marrakech 40000, Morocco \\ ${ }^{d}$ LP2M2E, Département de Physique Apliquée, Faculté des Sciences et Techniques, Avenue \\ Abdelkarim Elkhattabi B.P 549, Marrakech 40000, Morocco \\ ${ }^{e}$ ETRI, Faculté des Sciences Semlalia, Boulevard Prince My Abdellah, Marrakech 40000, Morocco \\ ${ }^{f}$ Office Régional de Mise en Valeur Agricole du Haouz, Avenue Hassan II, Guéliz, Marrakech 40000, \\ Morocco
}

*Corresponding author and current address: Salwa Belaqziz

Laboratoire Mixte International TREMA, Faculté des Sciences Semlalia, Université Cadi Ayyad, BP 2390 Marrakech Maroc,

Tel: (+212) (0) 663869921; Fax: (+212) (0) 524431626

Email: s.belaqziz@uca.ma

\begin{abstract}
Irrigation scheduling is an important task that significantly influences water conservation and crop production. For most gravity irrigation networks located in semi-arid areas, irrigation scheduling is based on available water regardless of crops water needs. The objective of this study is to propose a new approach for optimizing irrigation scheduling taking into account crops water demand, based on the Covariance Matrix Adaptation Evolution Strategy (CMA-ES) evolutionary strategy algorithm. The objective function, that must be minimized, of this optimization problem is defined as the sum of two terms. The first term is the Irrigation Priority Index (IPI) which characterizes the degree of imbalance between water stress and irrigation timing of the plot. The second one takes into account the various constraints that relate to canals capacity, tasks timing, geographical distances and canal flow rate variations. The approach was applied to an agricultural sector located at $40 \mathrm{~km}$ from the city of Marrakech (Morocco). Optimal schedule for the third irrigation, of the 2011-2012 agricultural season, is provided and the comparisons between schedules before and after optimization are made. The obtained results demonstrate that such approach allows reducing the proportion of late irrigated plots (from $22 \%$ to $8 \%$ ) and increasing the proportion of plots irrigated at an appropriate time (from $28 \%$ to $40 \%$ ). We conclude that this approach can be considered as an efficient tool for planning irrigation schedules by considering crops water needs.
\end{abstract}

Keywords: Irrigation scheduling, Evolutionary algorithm, optimization, gravity irrigation network, irrigation round. 


\section{Introduction}

Sustainable development has become a world concern major element aiming to use and manage rationally human, natural and economic resources in order to meet population's basic needs. Among natural resources, water is the most important and its sustainable management is a necessity, particularly in arid and semi-arid areas where crops development can be characterized by a limited predictability (Mangiarotti et al., 2012; Jarlan et al., 2014). Semi-arid areas occupy currently more than 30\% of the globe (Schlesinger et al., 1990) and have irregular water resources whilst water demand is increasing. Among the different sectors, irrigated agriculture consumes the largest volumes of water resources. In Morocco, it was pointed that uncontrolled irrigation management leads to an alarming situation (PAPNEEI, 2009). Therefore, it is necessary to develop effective solutions to save water and to adopt efficient strategies for the distribution of this resource in the most reasonable way. To ensure agriculture water use efficiency, it is necessary to improve its profitability by providing an irrigation schedule which optimizes the water supply according to real needs of each crop, taking into account environmental conditions, irrigation network constraints and agronomic conditions (Kharrou et al., 2011).

The scheduling and management of irrigation is essential. Several delivery methods are used in irrigated agriculture throughout the world, some of these approaches allocate water to different crops at farm level (Santhia and Pundarikanthan, 2000; Nixon et al., 2001; Playan and Mateos, 2006). Other studies cover larger scales, involving the development of indices and models (Al-Kaisi et al., 1997; Shang and Mao, 2006; Gontia and Tiwari, 2008; O'Shaughnessy et al., 2012; Belaqziz et al., 2013). Specific packages and algorithms related to irrigation management have also been addressed in some delivery scheduling models (Hess, 1996; Mohan and Arumugan, 1997). Most of the irrigation models previously developed are based on simulation techniques and also use optimization or scheduling algorithms. Such approaches were applied to different types of irrigation systems, but do not apply to the present problem, that is irrigation rounds in a gravity irrigation system.

The irrigation scheduling is thus the focus of this study. It consists in defining the sequence of irrigated plots and the associated water amount to be applied in order to satisfy all crops water requirements. We focus on the Haouz plain near Marrakech (Morocco) taken as a typical example of irrigated agriculture in semi-arid areas, and especially in the southern Mediterranean countries. In this region, gravity irrigation is the most widely used irrigation delivery method because it is less complex to implement and less demanding in terms of material resources at the plot scale compared to other systems (Taky et al., 2004). However, the implementation of this technique faces several problems: (1) the large variety of situations relating to the type of crop or ploughing, sowing dates, soil and climatic conditions that are difficult to take into account in the irrigation planning; (2) The constraints related to the irrigation network which have effect on the water delivery timing; (3) The decided numbers of water rotations before the agricultural season begins are based on the total available water without considering rain forecasts, and the water amounts allocated to the plots area without taking into account the type of crops; (4) the timing of irrigation may be based only on visual inspection of the crops by the farmers, which may cause either a water excesses or a water shortages; and (5) the bad irrigation scheduling: indeed, irrigation may sometimes coincides with a rainfall event.

The difficulties of scheduling irrigation may result in crop water stress or, on the contrary, water losses due to excess intake. However, applying the right amount of water at the correct time with a lower cost and lower water losses, taking human and technical constraints into account, remains a complex problem. This is increasingly the case where 
crops, soils and climatic conditions are contrasted and when the total volume of water is limited due to restrictions or scarcity. However with help of optimization techniques and models, it has been made possible to deal with such situation. Considerable research works have been done to develop mathematical models optimizing irrigation water management for different irrigation systems. Suryavanshi and Reddy (1986) for the first time proposed a 0-1 linear programming (LP) model for preparing the optimal operation schedule for irrigation canal outlets later improved by Wang et al. (1995); Reddy et al. (1999) and Anwar and Clark (2001). Other works by Garg and Ali (1998) and Tzimopoulos et al., (2011) were developed to solve a similar problem using linear programming. Naadimuthua (1999); Anwar and De Vries (2004) and Almiñana et al. (2010) introduced heuristic solutions which were shown to be more efficient compared with linear programming approaches. Wardlaw and Bhaktikul (2004) applied a genetic algorithm to the problem described by Anwar and Clark (2001) and claimed better solution quality by scheduling supplies as close as possible to the times requested by farmer. Ul Haq et al. (2008) demonstrated that heuristics such as genetic algorithms is computationally more efficient than the Integer Programming (IP) and appears to have considerable scope as a tool to solve the problem of preparing an irrigation schedule. Several other studies (Chen, 1997; Raju and Kumar, 2004; Mathur et al.; 2009; Elferchichia et al., 2009; Sharif and Wardlaw, 2000; Kuo et al., 2000) demonstrated the efficiency and the strength of genetic algorithm approach as an optimization tool to provide good solutions for an irrigation scheduling problem. Paly and Zell (2009) compared five Evolutionary Algorithms (Real Valued Genetic Algorithm, Particle Swarm Optimization, Differential Evolution, and two Evolution Strategy-based Algorithms) on the problem of irrigation optimization and showed that Differential Evolution and Particle Swarm Optimization are able to optimize irrigation schedules achieving results which are extremely close to the theoretical optimum.

A new irrigation scheduling approach is presented in this paper aiming to rationalize the water distribution in a classical gravity network based on an ad hoc index recently introduced to define the irrigation priority (Belaqziz et al., 2013). This index requires information about the crop water need which is based and estimated on a spatialized version of the FAO-56 method (Allen et al., 1998) guided by time series of remote sensing imagery (Simmoneaux et al., 2008; Er-Raki et al., 2010a). The rationalization is formulated as an optimization problem taking into account the main technical and human constraints of the irrigation. It is performed based on an evolutionary algorithm. The approach is applied to an irrigated sector located at $40 \mathrm{~km}$ from the city of Marrakech (Morocco) in the eastern part of the Tensift plain. The paper is organized as follows: the second section gives an outline of the study area and the irrigation method currently applied. The spatialized method used to estimate the soil water depletion is also presented. In the third section, the CMA-ES algorithm is introduced and the optimization approach is presented with a detailed description of the objective function formulation. Results are presented and discussed in the fourth section. Finally, the conclusions of this work are drawn in the last section.

\section{Presentation of the case study}

\subsection{Study area}

The study area is located $40 \mathrm{~km}$ east of the city of Marrakech (Morocco) in the eastern part of the Tensift plain. Centred on the geographical coordinates $7^{\circ} 39^{\prime} 4.16^{\prime \prime} \mathrm{W}$ and $31^{\circ} 41^{\prime} 33.90 " \mathrm{~N}$, this area, named "R3", has a 2800 ha surface and is mainly used for cereal crops (45\% in 2011-2012 and the remainder of the irrigated area corresponds to annual crops and tree crops). The climate of the region is semi-arid, characterized by high temperature in summer $\left(38^{\circ} \mathrm{C}\right.$ on average, in July) and mild temperature in winter $\left(5^{\circ} \mathrm{C}\right.$ on average, in 
February) (Er-Raki et al., 2010b). The annual precipitation average is about $250 \mathrm{~mm}$, whereas the evaporative demand is about $1500 \mathrm{~mm} / \mathrm{yr}$ (Duchemin et al., 2006).

\subsection{The irrigation network}

The study area is irrigated by a classical gravity network. Water is provided by the Hassan 1 dam located in the neighboring catchment of Oum Erabia through the Rocade canal, feeding two primary canals: P1 on the right bank of the sector and P2 on the left bank. In this work, we focus on the irrigation scheduling of the second primary canal R3P2 presented in Figure 1. Irrigation water is conveyed to each plot by a network of secondary and tertiary open air canals. The area is divided into irrigation blocks generally supplied by a tertiary canal. This later feeds a variable number (from 1 to 10) of blocks. Some of them are directly irrigated by the primary or secondary canals. The plot irrigation is done by flooding method.

The detailed data on irrigation distribution is provided by the Regional Office of Agricultural Development of Haouz (ORMVAH). The volume of water made available and the number of irrigation rounds (from 3 to 7) depends on the available water in early autumn and the volume accumulated during the winter season. The applied volume for irrigation water is calculated based on the duration of canal opening. The number of plots watered can vary at each irrigation round. This number relies principally on the farmer's choice and funds, but also on available water in the dam.

\subsection{The current irrigation method}

In collaboration with three farmers associations, the local ORMVAH centre is in charge of preparing the irrigation schedule according to the sowing dates and water availability in the dam; and managing the irrigation rounds. In practice, a global amount of water is assigned to the irrigation sector at the beginning of the agricultural season. The number of irrigation rounds, irrigation rounds starting dates and the volumes assigned to each round are discussed and fixed by managers and users.

At each round, the farmers receive an amount of water according to the owned area. This amount does not take into account the type of crops and its water requirement, even if some plots are uncultivated. As a consequence, an amount of water may be lost for the crop and the irrigation distribution is not always adapted to the crop needs and water stress level which may have indirect significant impact on growth and yields. At the plots scale, the level of complexity is compounded by the spatial heterogeneity of the sowing dates (Er-Raki et al., 2010a), the size of tilled plots, and the quantity of nitrogen used (Hadria et al., 2007). A high spatial and temporal heterogeneity of irrigation water results from this situation which complexity is not usually considered in water distribution. In such complex system, finding the optimal combination of irrigation starting times is difficult to formulate and obtain.

\subsection{Spatialized estimates of soil water depletion}

The water stress coefficient $\left(K_{s}\right)$ is a key factor that affects the growth, development and crop production. It allows characterizing the water needs of crops by calculating the water amount in the root zone. Based on the dual approach of FAO-56 method (Allen et al., 1998), the concept is to consider a fraction $W_{\mathrm{RA}}$ of readily available water, of the total available soil water at the root zone $W_{\mathrm{TA}}$, to be extracted by the crop without suffering water stress. $K_{s}=1$ (no stress) when there is no limitation to water uptake and $K_{s}<1$ (severe stress) when the available soil water is a limiting factor. $K_{s}$ is expressed as:

$$
K_{s}=\frac{W_{\mathrm{TA}}-D_{\mathrm{r}}}{W_{\mathrm{TA}}-W_{\mathrm{RA}}} \leq 1
$$


where $D_{\mathrm{r}}$ is the root zone depletion in $(\mathrm{mm})$, i.e. the water shortage relative to field capacity, when $D_{\mathrm{r}} \leq W_{\mathrm{RA}}, K_{\mathrm{s}}=1 . W_{\mathrm{TA}}$ is expressed by the difference between the water content at field capacity and wilting point:

$W_{\mathrm{TA}}=1000\left(\theta_{\mathrm{FC}}-\theta_{\mathrm{WP}}\right) Z_{\mathrm{r}}$

where $\theta_{\mathrm{FC}}$ is the water content at field capacity in $\left(\mathrm{m}^{3} \mathrm{~m}^{-3}\right), \theta_{\mathrm{WP}}$ the water content at wilting point in $\left(\mathrm{m}^{3} \cdot \mathrm{m}^{-3}\right)$ and $Z_{\mathrm{r}}$ the rooting depth in $(\mathrm{m})$ which varies according to the plant development. $W_{\mathrm{RA}}$, the fraction of $W_{\mathrm{TA}}$ is expressed by:

$W_{\mathrm{RA}}=\rho W_{\mathrm{TA}}$

where $\rho$ is the average fraction of $W_{\mathrm{TA}}$ that can be depleted from the root zone before moisture stress occurs.

Before each irrigation round, a map of the plot water stress $K_{\mathrm{S} i}$ corresponding to plot $i$, can be estimated. The SAMIR software (SAtellite Monitoring of IRrigation) (Simonneaux et al., 2009) is directly used for this purpose. This software uses satellite images to compute estimates of evapotranspiration and soil water budget over large areas.

\section{The optimization problem}

\subsection{Decision variables}

The object of this work is to rationalize water distribution taking into account the crops water demand in regard to available volumes, while respecting some constraints resulting from practical implementation of water distribution. Such problem can be viewed as an optimization problem. Optimization algorithms aim at finding the values of decision variables allowing for optimizing (minimizing or maximizing) a function called the objective function. This function has to be defined cautiously in order to properly characterize the optimization problem. The present optimization problem can be formulated as follows: given a gravity irrigation system subject to times constraints, flow rates constraints, irrigation network constraints and duration constraints of each canal regarding the crops needs, how to obtain a feasible (all the tasks can be performed) and optimal (a rational distribution of water) irrigation schedule?

During an irrigation round, it is assumed that the irrigation duration of a plot does not rely on the opening time, the closing time of each zone thus directly results from the opening time. The problem therefore relies on scheduling the dates of canals opening (the closing date being directly deduced from the crops needs). The opening times $\delta t_{i}$ can thus be taken as the only decision variables in the optimization process. 26 decision variables have to be considered when the constraints of the irrigation network are taken into account. 116 decision variables are necessary when assuming that irrigation constraints can be relaxed, that is, each plot can be irrigated independently from any others.

\subsection{Objective function}

Any constraint violation causes a schedule to become infeasible. Indeed, by precluding the estimation of the objective function where constraints are not satisfied, strict constraints may impede the exploration of decision variables space. In practice, a penalty method can be introduced to control infeasibility. The penalty method consists in turning a strict constraint into a smoother one to suit the application of evolutionary computing techniques. It is thus chosen to formulate constraints as a penalty rather than a prohibitive constraint, and to include this penalty in the objective function. The objective function $F$ will thus include two parts:

$$
F=F_{1}+F_{2}
$$


The role of the first term $F_{1}$ is to rationalize the water distribution by considering the need of water; an irrigation criterion named Irrigation Priority Index (IPI) presented in Belaqziz et al., (2013) is used to satisfy this objective. The role of the second term $F_{2}$ is to take the practical constraints into account in a smooth manner in order to guaranty the exploration of decision variables space in an effective way. Based on this formulation the aim of the optimization problem can be stated as follows:

$\arg \min F$

$\left\{x_{k}\right\}_{k=1 . . N} \in \Re$

where $\left\{x_{k}\right\}_{k=1 . . N}$ corresponds to the optimized schedule of $N$ opening/closing tasks to be performed. Optimal IPI index $\gamma^{\mathrm{opt}}$ and optimal values of $F_{1}^{\mathrm{opt}}$ and $F_{2}^{\mathrm{opt}}$ also rely on Eq. 4.

The IPI criterion $\gamma$ is an ad hoc index that characterizes the priority irrigation of each plot at each irrigation round for a specific area (Belaqziz et al., 2013). It is ad hoc because it can only refer to the chosen area and does not allow any comparison between different areas. It is also a relative criterion since it allows distinguishing the heterogeneities inside the area of study in terms of irrigation priority. It applies to heterogeneous areas which plants may undergo any level of water stress from none to very high. Once the area of study is chosen, this index can be calculated for each plot $i$ and expressed as a linear function of two terms, one accounting for the water stress of the crop, another one accounting for the irrigation delay after the irrigation round is started. The index of plot $i$ is expressed as follows:

$\gamma_{i}=\frac{K_{\mathrm{S} i}-K_{\mathrm{S}}^{\min }}{K_{\mathrm{S}}^{\max }-K_{\mathrm{S}}^{\min }}-\frac{\delta t_{i}}{T}$

round, and $K_{\mathrm{S}}^{\min }$ and $K_{\mathrm{S}}^{\max }$ are the spatial minimum and maximum of the $K_{\mathrm{S}}$ map, that is the most and less stressed plots, respectively. $\delta t_{i}$ is the time delay (in days) between the beginning time of the irrigation round and the irrigation time of plot $i$ and $T$ the irrigation day of the last plot, that is $T=\delta t_{\mathrm{i}}^{\max }$. Values of $\delta t_{i}$ range between 0 and $T$ and are chosen as the decision variables of the optimization process.

Equation (6) ranges the IPI values between -1 and +1 . Extreme values reflect a non rational water monitoring, $\gamma=-1$ corresponding to the most stressed plot irrigated the last day of the irrigation round; $\gamma=+1$ to the less stressed plot irrigated in first. Contrarily, $\gamma=0$ corresponds to a reasonable tradeoff between level of stress and irrigation delay. Therefore, value of $\gamma$ close to 0 is an indicator of optimal water distribution during an irrigation round.

In practice, irrigation scheduling relies on canals and irrigation cannot be scheduled plot by plot individually but canal by canal. To consider the optimization of all the plots, the $\gamma$ index should thus be considered on the average of plot groups irrigated by the same canal. It should be also noted that the dynamical response to water stress is, by nature, dissymmetrical: under stress conditions, a late irrigation may lead to severe damages for the crop impacting its development and production than an early one. In other words, a moderately negative index may have severe impact on the crops whereas a moderately positive index may just require a moderate over-consumption of water. Such a dissymmetry may be advantageously introduced into the objective function. To do so, the first term of the objective function is expressed as follows:

$F_{1}=\sum_{k=1}^{N}\left(\gamma_{k}-\gamma^{d}\right)^{2}$

where $k$ is the canal index, $N$ the total number of canals, and $\gamma^{d}$ the index shift to take into account for the dissymmetrical response to stress. 


\subsection{Constraints}

Five constraints are identified which present a decreasing level of priority. (1) The capacity constraint ensures that supplies can never exceed the total capacity of the canal. (2) The interval constraint ensures that all the irrigation tasks can be scheduled during the irrigation round which dates of earlier possible beginning and later possible ending are fixed. (3) The overlap constraint ensures that all the practical actions can be applied consistently (all actions can be performed but several actions cannot be performed simultaneously), taking into account (4) the geographical distance between the locations where the actions must be applied and the irrigation time span required for all the plots of a same canal. (5) The daily working time of operators. These constraints are formulated as a weighted sum of functions:

$$
F_{2}=\sum_{j=1}^{5} r_{j} P_{j}
$$

where $r_{j}$ is the weight associated to each constraint $j$, chosen arbitrarily in order to give more or less priority to the constraints; and $P_{j}$ the corresponding penalty. The penalty is expressed as:

$$
P_{j}=\sum_{k=1}^{N} v_{j, k}
$$

where $N$ is the total number of tasks to be applied and the $k^{\text {th }}$ task is such as $v_{j, k}=0$ if the task is satisfying the constraints, $v_{j, k}=1$ otherwise. In practice, all the tasks are considered at the end of each simulation from which the $P_{j}$ are estimated. More specific descriptions of the constraints are given hereafter.

\subsubsection{The flow rate constraint}

The flow rate constraint ensures that, at any time, the supply did never exceed the discharge capacity $\Theta, Q$ and $q$ of the primary, secondary and tertiary canals respectively (in $m^{3} s^{-1}$ ). The constraint can be expressed as:

$$
\begin{aligned}
& \sum_{j=1}^{J} Q_{j}(\delta t) \leq \Theta(\delta t) \\
& \sum_{i, j=1}^{I J J} q_{i j}(\delta t) \leq Q_{j}(\delta t)
\end{aligned}
$$

where $i$ and $j$ denote the tertiary and secondary canals' number, respectively, opened at the same time $\delta t$.

\subsubsection{Irrigation interval constraint}

The irrigation interval constraint ensures that all the tasks were scheduled within the specified irrigation round interval, that is:

$$
\begin{aligned}
& \delta t_{\text {start }} \leq \delta t_{i} \leq E \\
& \delta t_{i}+D_{i} \leq E
\end{aligned}
$$

where $\delta t_{\text {start }}$ refers to the starting time of the irrigation round; $\delta t_{i}$ the opening time scheduled for canal $i$; $E$ the total duration allowed for the irrigation round, and $D_{i}$ the total irrigation duration scheduled for the plots supplied by canal $i$. 


\subsubsection{Overlap, travel time and time working constraints}

An operator cannot perform several tasks simultaneously, considering that each canal opening or closing task requires a time span shorter than $15 \mathrm{~min}$. (traveling time not included). The traveling time required for the operator to travel by moped from one canal gate to another to perform the opening/closing actions obviously depends on the distance between canals which can be significant. The travel time between two gates is estimated linearly considering the spatial distance between two points and assuming a moving speed of $30 \mathrm{~km} \mathrm{~h}^{-}$ 1 . Finally, each task (open or close a canal) is to be scheduled within the specified working time that is between $8 \mathrm{~h} 00$ and $18 \mathrm{~h} 00$.

\subsection{Optimization algorithm}

The present optimization problem can be seen as the imbrications of three coupled problems: a basic scheduling, a locally linear optimization problem and a traveling salesman problem. This nesting makes the problem difficult to formulate simply. The Covariance Matrix Adaptation - Evolution Strategy (CMA-ES) algorithm (Hansen et al., 2003) is used to perform the optimization of such problem. Evolution Strategy algorithms belong to the class of the metaheuristic techniques and distinguish from Genetic algorithm in the adaptation of the algorithm parameters that control the search of optimal solution, as a function of the objective function under exploration. At present, the CMA-ES algorithm is one of the most powerful techniques for optimization of single-objective problems, where the multivariate normal distribution has a mean and a covariance matrix continually updated during the optimization process. Benchmarking of several algorithms has established that CMA-ES is one of the most efficient metaheuristics for dealing with difficult numerical optimization problems (Hansen et al., 2010). Another reason to prefer such algorithm is that a modification of the constraints may not require a reformulation of the problem, which, in practice, may be of considerable usefulness. This choice may thus also have some operational advantages.

In order to avoid local solutions by providing practical a "a priori" solutions which may bias the optimization approach, it was preferred to simulate the initial parameterization of the search algorithm randomly, and to reiterate the algorithm 10 times. Such ensemble of run will also allow checking that the best results are independent from the initial seed of decision variables which are chosen randomly to initialize the algorithm. The solution corresponding to the lower value of $F$ among final solutions is considered as the optimal solution (see Eq. 5). This search process is summarized in Figure 2. Five input parameters are required to run the optimization algorithm: (1) the total irrigation duration corresponding to each canal. This time span is deduced from the volume of water required for each plot to meet the needs of the crops, as provided by the SAMIR software. (2) The map of water stress before the irrigation round, which is required to estimate the $\gamma$ index, is also obtained from the SAMIR software. (3) The irrigation network, which is used to estimate the traveling times between canal gates. And the parameterization of the CMA-ES optimization itself: the number of iterations (4) has been chosen as 200 and the population (5) size chosen such as $\lambda=$ 600. Finally (6) the CMA-ES also requires one initial solution associated with an initial variance of the distribution, used to generate the initial population set.

\section{Results and discussion}

Focus is put on the third irrigation round of the 2011-2012 agricultural season because crops are well developed and the water needs are significant. This round lasted from 9th to 23th of February 2012. The map of the $K_{\mathrm{S}}$ stress coefficient before the irrigation round is displayed in Figure 3a (heterogeneity at higher scale is discussed below). At this date, an important contrast can be observed in the area of study with, broadly speaking, a low level of 
stress observed in the southern part, a high level in the east and west zones which are very patchy, and a moderate level of stress elsewhere. As a reminder, the achieved scheduling at this time was based on the water amount available into the dam, such that at each irrigation round, farmers receive a water volume according to the plot area. A map of the $\gamma$ index that was practically applied can thus be reconstructed (Belaqziz et al., 2013). This map is shown in Figure $3 \mathrm{~b}$ from which three types of behavior can be distinguished: areas of stress (accounting about $19 \%$ of the total surface) for which irrigation was applied too late, that is with $\gamma$ indices lower than -0.2 (in black); areas out of stress (54\%) for which irrigation was applied too early, with $\gamma$ indices greater than +0.2 (dark gray), and areas for which irrigation was applied appropriately (27\%), that is with $\gamma$ indices between -0.2 and +0.2 (light gray). These results are summarized in Table 1.

By applying the optimization procedure presented above with a dissymmetrical shift set to zero $\left(\gamma^{d}=0\right)$, a first schedule was obtained. The convergence of the algorithm is illustrated in Figure 4 for one of the runs. A small range of control parameters is explored during the first hundred iterations of the optimization (see Figure 4b). The necessity to enlarge this range is detected by the CMA-ES algorithm, the covariance is then adapted which allows reducing rapidly the objective function (Figure. 4a). The optimization process is then pursued which allows refining the parameter search till the convergence is reached. To evaluate the robustness of the results, it was checked that the randomly chosen initial values of the decision variable (see Figure. 5a) would lead to similar optimized values. The optimal values obtained for the 10 runs are often undistinguishable from one to another (see Figure. 5b, plain grey lines). A sensitivity analysis was also performed in order to test the robustness of the results. Numerous factors may introduce uncertainty in the results. These factors include satellite data error, modeling approximation, imprecise parameterization model, etc. These errors are difficult to characterize and to estimate. The error of the water stress $K_{\mathrm{S}}$ resulting from the combinations of these factors was assumed to be equivalent to an error level of $5 \%$. Based on this hypothesis, an additive Gaussian noise of $5 \%$ was added to the $K_{\mathrm{S}}$ before the optimization was processed. These perturbations led to moderately modify the optimal decision variables (see Figure. 5b, dotted grey lines) confirming the robustness of the results.

All the constraints could be satisfied except for six actions for which the last constraint of working time was not compatible with the working day, leading to a minimum value of $F_{2}$ different from 0 (Figure 4a; dark gray). This means that exceptional tasks should be managed, or that a preemptive scheduling for all the tasks may be tried. A map of the $\gamma$ index was reconstructed from this optimized schedule (Figure $3 \mathrm{c}$ ). The resulting indices clearly illustrate the efficiency of the optimization approach by obtaining values of $\gamma$ close to zero everywhere in the area of study. This efficiency is fully salient by considering the distributions of the $\gamma$ indices by canal, before and after optimization (Figure 6a). The distribution is very dispersed and covers a very large range of the IPI before optimization whereas all the indices are concentrated between -0.2 and +0.2 , after.

However, as shown in Figure 7a, an important spatial heterogeneity of water stress is clearly observed between the plots irrigated by the same canal. This heterogeneity results from the choice of crops variety (durum or bread wheat, barley, olives or beet), the sowing dates, the size of tilled plots, the quantity of nitrogen used, and also from the pedology (soil type and thickness) which exhibits slight variations in the area of study (Hadria et al., 2007). Estimates of the $\gamma$ indices can thus also be mapped at the plot scale. Values corresponding to the practical case are plotted in Figure $7 \mathrm{~b}$. As expected, the map clearly exhibits a high number of plots (about 50\%) under low stress for which an early irrigation was applied $(\gamma>+0.2)$ and $22 \%$ of plots under high stress are irrigated lately $(\gamma<-0.2)$ whereas only 
few plots $(28 \%)$ were irrigated at the appropriate time $(-0.2<\gamma<+0.2)$. These results are summarized in Table 2 . At the plots scale, it is found that the optimization is only marginally able to improve the results (see Figure 6b). This limited improvement does not directly arise from the definition of the $\gamma$ index which aim is to characterize the heterogeneity in terms of priority. Such difficulty results - in first - from the practical constraints of the irrigation network which do not allow for independent irrigation of plots alimented by the same canal. Indeed, as mentioned before, the optimization approach perfectly allowed for centering the distribution around zero, but with large dispersion resulting from the important heterogeneity of the plot indices which cannot be optimized for a group of plots corresponding to the same canal. This limited improvement also results - in second - from the symmetrical and linear formulation of the IPI criterion, which assumes that the balance between the water stress and the irrigation time can be formulated mathematically in a symmetrical and proportional way. This difficulty was solved by introducing a dissymmetrical shift $\gamma^{d}=+0.2$ in order to promote moderately earlier irrigation rather than water stress. By shifting the distribution of the $\gamma$ indices on the right, this modification allows avoiding strong stresses.

Applying this shift, the optimized schedule (see Figure 7c) leads to a narrower range of plots irrigated lately (about $8 \%$ with $\gamma<-0.2$ ) and a wider range of plots irrigated early (about 52\% with $\gamma>+0.2$ ) or irrigated in time regarding their relative levels of water stress (about $40 \%$ with $-0.2<\gamma<+0.2$ ). In other words an early irrigation is systematically preferred, which is favorable for a yield increase (Belaqziz et al., 2013).

This only moderate improvement of IPI values is mainly due to the irrigation constraints, especially those related to irrigation network which does not permit to take the spatial heterogeneity of water stress. If the plots could be irrigated independently, the results would be significantly different. This situation was simulated by performing an optimization assuming that the 116 plots could be irrigated separately, even when depending on the same canal. The obtained results after optimization show that the proportion of irrigated plots in time is obviously improved (89\% with $-0.2<\gamma<+0.2$, see Table 2 ) and the proportion of plots early or late irrigated becomes quite low $(0 \%$ with $\gamma<-0.2$ and $11 \%$ with $\gamma>+0.2)$.

A comparison of the water quantities that would be consumed when using the present scheduling approach with the amounts which were presently allocated for irrigation was also performed. This comparison could be achieved for each tertiary canal (see Fig. 8). Since based on independent evaluations of the crop needs, applied and estimated water amounts can differ significantly. Although not systematic, a generally lower amount of water was prescribed by the SAMIR tool. While improving water scheduling with regards to crops water need, this comparison also shows that an optimized scheduling may achieve a reduction of more than $25 \%$ of consumption of water resources ranging from an amount of $580280 \mathrm{~m}^{3}$ to $429440 \mathrm{~m}^{3}$. Such reduction would be considerable.

\section{Conclusion}

The rationalization of irrigation in a classical gravity network is considered in this study. The problem is viewed as an optimization problem in which control is ensured by irrigation scheduling. An approach is developed to obtain rationalized solutions accounting for the practical monitoring of irrigation. The ad hoc Irrigation Priority Index is used to balance irrigation time with water stress. Crop water stress is derived from the SAMIR software controlled by satellite images. An evolutionary algorithm, the CMA-ES algorithm, is used to perform the optimization.

The approach is applied to the third irrigation round of the 2011-2012 agricultural season in a gravity irrigation network located at the eastern part of the Tensift Al-Haouz plain. 
The approach shows a very good efficiency and allows providing an optimized schedule of the irrigation. Nonetheless, because the practical monitoring of the network does not allow for rescheduling freely the plots irrigation supplied by a same canal, some of the heterogeneity cannot be solved by the approach. To take this heterogeneity into account, a dissymmetrical term is introduced in the objective function in order to rationally foster early irrigation rather than water stress. The approach shows a high efficiency by allowing rationalization of irrigation scheduling, amount of water to be provided, and by avoiding high levels of water stress.

The optimization approach could allow significant decreasing proportion of late irrigated plots (from $22 \%$ to $8 \%$ ) and increasing proportion of plots irrigated at appropriate time (from $28 \%$ to $40 \%$ ). Therefore, we conclude that the proposed approach is computationally efficient and robust to optimize irrigation scheduling in a gravity irrigation network.

In this semi-arid area, water restrictions leads to common appearance of hydric stress, making the use of $K_{\mathrm{s}}$ relevant for irrigation scheduling. Nevertheless, further investigations should be performed by considering the root zone depletion $D_{\mathrm{r}}$ instead of the water stress coefficient $K_{\mathrm{s}}$. However, this would require the definition of another priority criterion.

An optimized irrigation scheduling may also achieve potentially a significant $25 \%$ reduction of water consumption. Such reduction may be investigated under real condition in a future work in order to check its practical interest and, especially, its potential consequences in terms of yields that will, eventually, be the only guarantee of the approach operational efficiency.

\section{Acknowledgements}

This research was conducted within the International Joint Laboratory TREMA (Télédétection et Ressources en Eau en Méditerranée semi-Aride, http://trema.ucam.ac.ma/) as well as the RS/09/2011 project financed by the CNRST of Morocco. The authors would like to thank the MISTRALS/SICMED program, CESBIO and the IRD for financial support. CNES is also acknowledged for access to the SPOT5 images through the ISIS program. The staff of the Regional Office of Agricultural Development ORMVAH is also kindly acknowledged for their assistance during the course of this study. The implementation of CMA-ES used here was adapted from the original code by Nikolaus Hansen from TAO team in INRIA. We are grateful to Marc Schoenauer for helpful interactions.

\section{References}

Al-Kaisi, M.M., Berrada, A., Stack, M., 1997. Evaluation of irrigation scheduling program and spring wheat yield response in southwestern Colorado. Agric. Water Manag. 34, 137148.

Allen, R.G., Pereira, L.S., Raes, D., Smith, M., 1998. Crop Evapotranspiration: Guidelines for computing crop water requirements. Irrigation and Drainage Paper No. 56, FAO, Rome, Italy $300 \mathrm{p}$.

Almiñana, M., Escudero, L.F., Landete, M., Monge, J.F., Rabasa, A., Sanchez-Soriano, J., 2010. WISCHE: A DSS for water irrigation scheduling. OMEGA 38, 492-500.

Anwar, A.A., Clarke, D., 2001. Irrigation scheduling using mixed-integer linear programming. J. Irrig. Drain Eng. ASCE 127 (2), 63-69.

Anwar, A.A., De Vries, T.T., 2004. Irrigation scheduling II: Heuristics approach. J. Irrig. Drain. Eng. 130 (1), 17-25.

Belaqziz, S., Khabba, S., Er-Raki, S., Jarlan, L., Le Page, M., Kharrou, M.H., El Adnani, M., Chehbouni G., 2013. A new irrigation priority index based on remote sensing data for assessing the networks irrigation scheduling. Agric. Water Manag. 119, 1-9. 
Chen, Y.M., 1997. Management of water resources using improved genetic algorithms. Comput. Electron. Agric. 18 (2-3), 117-127.

Duchemin, B., Hadria, R., Erraki, S., Boulet, G., Maisongrande, P., Chehbouni, A., Escadafal, R., Ezzahar, J., Hoedjes, J.C.B., Kharrou, M.H., Khabba S., Mougenot, B., Olioso, A., Rodriguez, J-C., Simonneaux, V., 2006. Monitoring wheat phenology and irrigation in Central Morocco: on the use of relationships between evapotranspiration, crops coefficients, leaf area index and remotely-sensed vegetation indices. Agric. Water Manag. 97 (1), 1-27.

Elferchichi, A., Gharsallah, O., Nouiri, I., Lebdi, F., Lamaddalena, N., 2009. The genetic algorithm approach for identifying the optimal operation of a multi-reservoirs on-demand irrigation system. Biosyst. Eng. 102, 334-344.

Er-Raki, S., Chehbouni, A., Duchemin, B. 2010a. Combining satellite remote sensing data with the FAO-56 dual approach for water use mapping in irrigated wheat fields of a semi-arid region. Remote Sensing. 2010; 2(1): 375-387.

Er-Raki, S., Chehbouni, A., Khabba, S., Simonneaux, V., Jarlan, L., Ouldbba, A., Rodriguez, J.C., Allen, R., 2010b. Assessment of reference evapotranspiration methods in semi-arid regions: Can weather forecast data be used as alternate of ground meteorological parameters? J. Arid Environ. 74, 1587-1596.

Garg, N.K., Ali, A., 1998. Two level optimization model for lower Indus basin. Agric. Water Manag. 36, 1-21.

Gontia, N.K., Tiwari, K.N., 2008. Development of crop water stress index of wheat crop for scheduling irrigation using infrared thermometry. Agric. Water Manag. 95, 1144-1152.

Hadria, R., Khabba, S., Lahrouni, A., Duchemin, B., Chehbouni, A.G., Ouzine, L., Carriou, J., 2007. Calibration and validation of the shoot growth module of STICS crop model: application to manage water irrigation in the Haouz plain, Marrakech plain. Arab. J. Sci. Eng. 31 (1C), 87-101.

Hansen, N., Auger, A., Ros, P.P.R., Finck, S., 2010. Comparing results of 31 algorithms from the black-box optimization benchmarking bbob-2009. In GECCO'10: Proceedings of the 12th annual conference comp on Genetic and evolutionary computation, pages 1689-1696, New York, NY, USA, ACM.

Hansen, N., Müller, S.D., Koumoutsakos, P., 2003. Reducing the time complexity of the derandomized evolution strategy with covariance matrix adaptation (CMA-ES). Evol. Comput. 11 (1), 1-18.

Hess, T., 1996. A microcomputer scheduling program for supplementary irrigation. Comput. Electron. Agric. 15 (3), 233-243.

Jarlan L., Driouech F., Tourre Y., Duchemin B., Bouysse M., Abaoui J., Ouldbba A., Mokssit A. and Chehbouni G., 2013, Spatio-temporal variability of vegetation cover over Morocco (1982-2008): linkages with large scale climate and predictability, International Journal of Climatology, 34(4), 1245-1261.

Kharrou, M.H., Er-Raki, S., Chehbouni, A., Duchemin, B., Simonneaux, S., LePage, M., Ouzine, L., Jarlan, L. 2011. Water use efficiency and yield of winter wheat under different irrigation regimes in a semi-arid region. Agricultural Sciences, 2 (3), 273-282.

Kuo, S.F., Merkleyb, G., P., Liu, C.W., 2000. Decision support for irrigation project planning using a genetic algorithm. Agric. Water Manag. 45 (3), 243-266.

Mangiarotti S., Coudret R., Drapeau L. \& Jarlan L., 2012. Polynomial search and Global modelling: two algorithms for modeling chaos. Physical Review E 86(4), 046205.

Mathur, Y.P., Sharma, G., Pawde, A.W., 2009. Optimal Operation Scheduling of Irrigation Canals Using Genetic Algorithm. International Journal of Recent Trends in Engineering 6, $11-15$.

Mohan, S., Arumugan, N., 1997. Expert system applications in irrigation management: an overview. Comput. Electron. Agric. 17, 263-280. 
Naadimuthua, G., 1999. A Heuristic Dynamic Optimization Algorithm for Irrigation Scheduling. Math. Comput. Model. 30, 169-183.

Nixon, J.B., Dandy, G.C., Simpson, A.R., 2001. A genetic algorithm for optimizing offfarm irrigation scheduling. J. Hydroinform. 3 (1), 11-22.

O'Shaughnessy, S.A., Evett, S.R., Colaizzi, P.D., Howell, T.A., 2012. A crop water stress index and time threshold for automatic irrigation scheduling of grain sorghum. Agric. Water Manag. 107, 122-132.

Paly, M., Zell, A., (Eds.), 2009. Optimal Irrigation Scheduling with Evolutionary Algorithms, In proceeding of: Applications of Evolutionary Computing, (EvoWorkshops 2009), pp. 142-151, Springer, Lecture Notes in Computer Science, Vol. 5484, Heidelberg, Germany, 2009. PAPNEEI, (Eds.), 2009. Appui au Programme National d'Économie d'Eau d'Irrigation - Plan de Gestion Environnemental et Social. Rapport interne, Ministère de l'Agriculture et de la Pêche Maritime, Maroc, pp. 51.

Playan, E., Mateos, L., 2006. Modernization and optimization of irrigation systems to increase water productivity. Agric. Water Manag. 80, 100-116.

Reddy, J. M, Wilamowski, B. ,Sharmasarakar, F.C, 1999. Optimal scheduling of irrigation for lateral canals. ICID Journal 48 (3), 1-12.

Santhia, C., Pundarikanthan, N.V., 2000. A new planning model for canal scheduling of rotational irrigation. Agric. Water Manag. 43 (3), 327-343.

Schlesinger, W.H., Reynolds, J.F., Cunningham, G.L., Huenneke, L.F., Jarrell, W.M., Virginia, R.A., Whitford, W.G., 1990. Biological feedbacks in global Desertification. Science 247, 1043-1048.

Shang, S., Mao, X., 2006. Application of a simulation based optimization model for winter wheat irrigation scheduling in North China. Agric. Water Manag. 85 (3), 314-322.

Sharif, M., Wardlaw, R., 2000. Multireservoir systems optimization using genetic algorithms: case study. J. Comp. Civil Engin. ASCE 14, 255-263.

Simonneaux V., Duchemin B., Helson D., Er-Raki S., Olioso A., Chehbouni AG. 2008. The use if high-resolution image time series for crop classification and evapotranspiration estimate over an irrigated area in central Morocco. International Journal of Remote Sensing 29(1): 95-116.

Simonneaux, V., Le Page, M., Helson, D., Metral, J., Thomas, S., Duchemin, B., Cherkaoui M., Kharrou, M.H., Berjami, B., Chehbouni, A. 2009. Estimation spatialisée de l'Evapotranspiration des cultures irriguées par télédétection. Application à la gestion de l'Irrigation dans la plaine du Haouz (Marrakech, Maroc). Sécheresse 20 (1), 123-130.

Srinivasa Raju, K., Nagesh Kumar, D., 2004. Irrigation Planning using Genetic Algorithms. Water. Resour. Manag. 18 (2), 163-176.

Suryavanshi, A.R., Reddy, J.M., 1986. Optimal operation schedule of irrigation distribution systems. Agri. Water Manag. 11, 23-30.

Taky, A., Mailhol, J.C., Debbarh, A., Bouarfa, S., Hammani, A., Zimmer, D., Ruelle, P., Belabbes, K., 2004. Diagnostic des pratiques d'irrigation gravitaire et possibilités d'amélioration dans le Gharb au Maroc. Projet INCO-WADEMED, Actes du Séminaire Modernisation de l'Agriculture Irriguéee, Rabat, Maroc.

Tzimopoulos, C., Balioti, V., Evangelides, C., Yannopoulos, S.T., 2011. Irrigation network planning using linear programming. Proceedings of the 12th International Conference on Environmental Science and Technology, Rhodes, Greece 8-10.

Ul Haq, Z., Anwar, A.A., Clarke, D., 2008. Evaluation of a Genetic Algorithm for the Irrigation Scheduling Problem. J. Irrig. Drain. Eng. 134 (6), 737-744.

Wang, Z., Reddy, J.M., Feyen, J., 1995. Improved 0-1 programming model for optimal flow scheduling in irrigation canals. Irrig. And Drain. Syst. 9, 105-116. 
Wardlaw, R., Bhaktikul, K., 2004. Comparison of Genetic Algorithm and Linear Programming Approaches for Lateral Canal Scheduling. J. Irrig. Drain Eng. ASCE 130 (4), 311-317. 


\section{Table caption}

Table 1: Obtained results at the aggregated scale (grouped plots). The ranges results from the $K_{s}$ perturbations.

Table 2: Obtained results at the plots scale. The ranges results from the $K_{\mathrm{s}}$ perturbations. 
Table 1

\begin{tabular}{lccc} 
& \multicolumn{3}{c}{ aggregated plots } \\
\cline { 2 - 4 } & without optimization & \multicolumn{2}{c}{ with optimization } \\
\cline { 3 - 4 } & $19 \%$ & $0 \%$ & {$[0 \%, 0 \%]$} \\
\hline $\mathrm{IPI}<-0.2$ & $27 \%$ & $100 \%$ & {$[69 \%, 100 \%]$} \\
$\mathrm{IPI}>+0.2$ & $54 \%$ & $0 \%$ & {$[0 \%, 19 \%]$} \\
\hline
\end{tabular}


Table 2

\begin{tabular}{|c|c|c|c|c|c|}
\hline & \multirow{2}{*}{\multicolumn{5}{|c|}{ Non-aggregated plots }} \\
\hline & & & & & \\
\hline & \multirow{3}{*}{$\begin{array}{c}\text { without } \\
\text { optimization }\end{array}$} & \multicolumn{4}{|c|}{ with optimization } \\
\hline & & \multicolumn{2}{|c|}{ with constraints } & \multicolumn{2}{|c|}{ without constraints } \\
\hline & & Optimal solution & Range & Optimal solution & Range \\
\hline $\mathrm{IPI}<-0.2$ & $22 \%$ & $8 \%$ & {$[8 \%, 9 \%]$} & $0 \%$ & {$[0 \%, 0 \%]$} \\
\hline$-0.2<\mid \mathrm{PI}<+0.2$ & $28 \%$ & $40 \%$ & {$[39 \%, 40 \%]$} & $89 \%$ & {$[64 \%, 89 \%]$} \\
\hline$|P|>+0.2$ & $50 \%$ & $52 \%$ & {$[52 \%, 53 \%]$} & $11 \%$ & {$[11 \%, 36 \%]$} \\
\hline
\end{tabular}




\section{Figure captions}

Figure 1: The hierarchical irrigation network of the studied area. The primary canal R3P2 (thick lines) distribute water to the 217 plots through the secondary (dark lines) and the tertiary canals (thin lines).

Figure 2: Flowchart of the optimization procedure.

Figure 3: Map of the water stress coefficient $K$ s averaged by canal areas just before the third irrigation round, February 8th 2012 (a); Map of the $\gamma$ index averaged by canal areas without optimization, same date (b); and $\gamma^{\mathrm{opt}}$ index obtained with the optimization for each canal areas, same date (c).

Figure 4: Convergence of the function F1 (light gray), F2 (dark gray) and resulting objective function F $=\mathrm{F} 1+\mathrm{F} 2$ (black) during the optimization process (a). Convergence of the control parameters is also provided (b).

Figure 5: Random initial values (a) and final optimal solution (b) of the decision variables. The very best solutions corresponding to the minimal objective function $F$ (black bold); the best results obtained for each optimized run based on the randomly chosen initial values of the decision variables presented in (a) (plain grey lines); and the best results for each optimized run under perturbed $K_{\mathrm{S}}$ conditions (dashed grey lines).

Figure 6: Distribution of the $\gamma$ indexes intervals for canals (a) and for plots (b) when no optimization (solid line) and with the centered $\left(\gamma^{d}=0\right.$ ) optimization (dashed line) and with the shifted $\left(\gamma^{d}=+0.2\right)$ optimization (dotted line).

Figure 7: Same as Figure 3, except that $K \mathrm{~s}(\mathrm{a}), \quad \gamma$ index (b) and $\gamma^{\mathrm{opt}}$ (c) index are not averaged by canal areas but directly calculated for each plot.

Figure 8: Comparison between the applied and estimated water amounts (in $\mathrm{m} 3$ ) at each of the 26 tertiaries. 
Figure 1

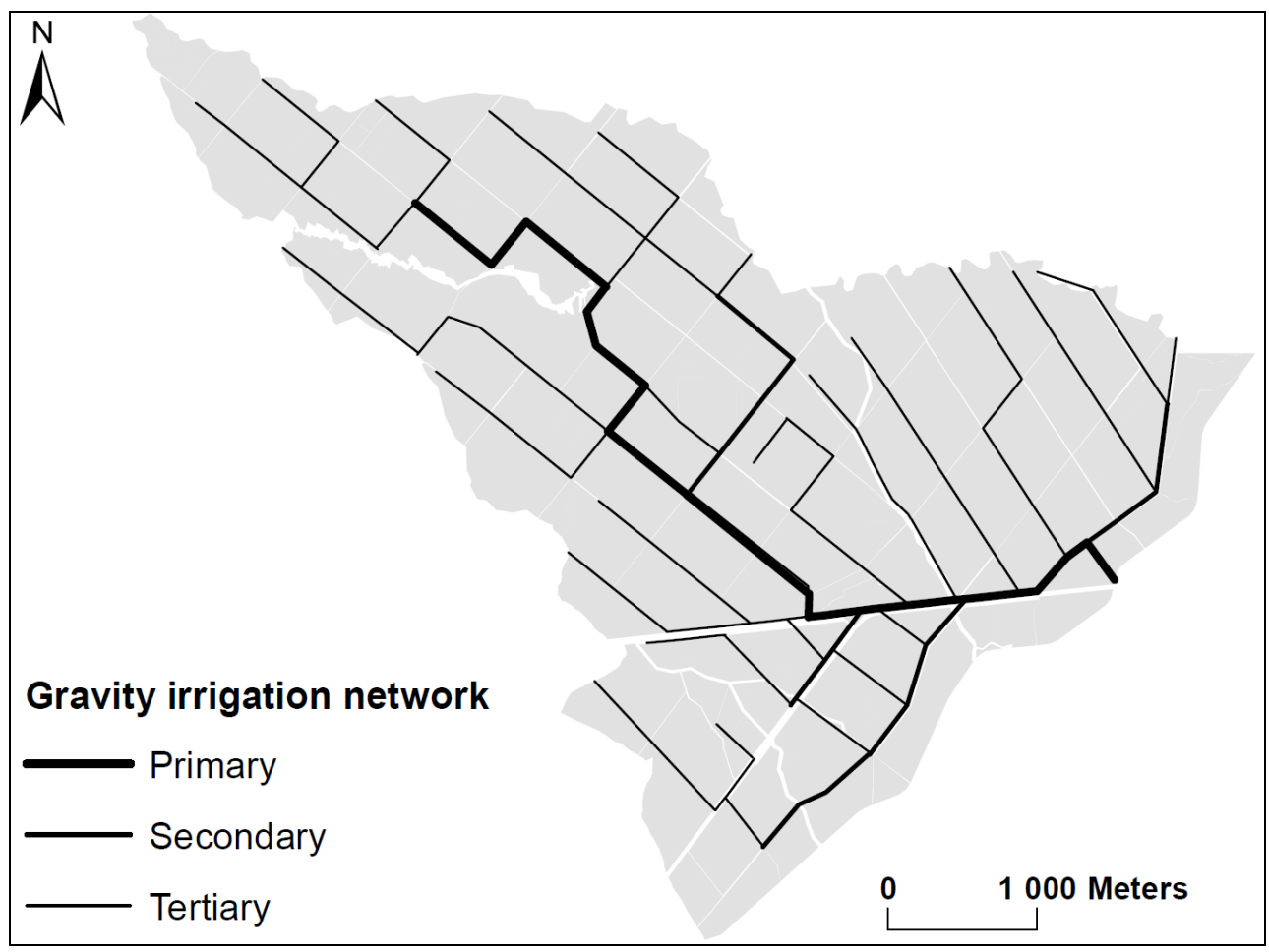




\section{Figure 2}

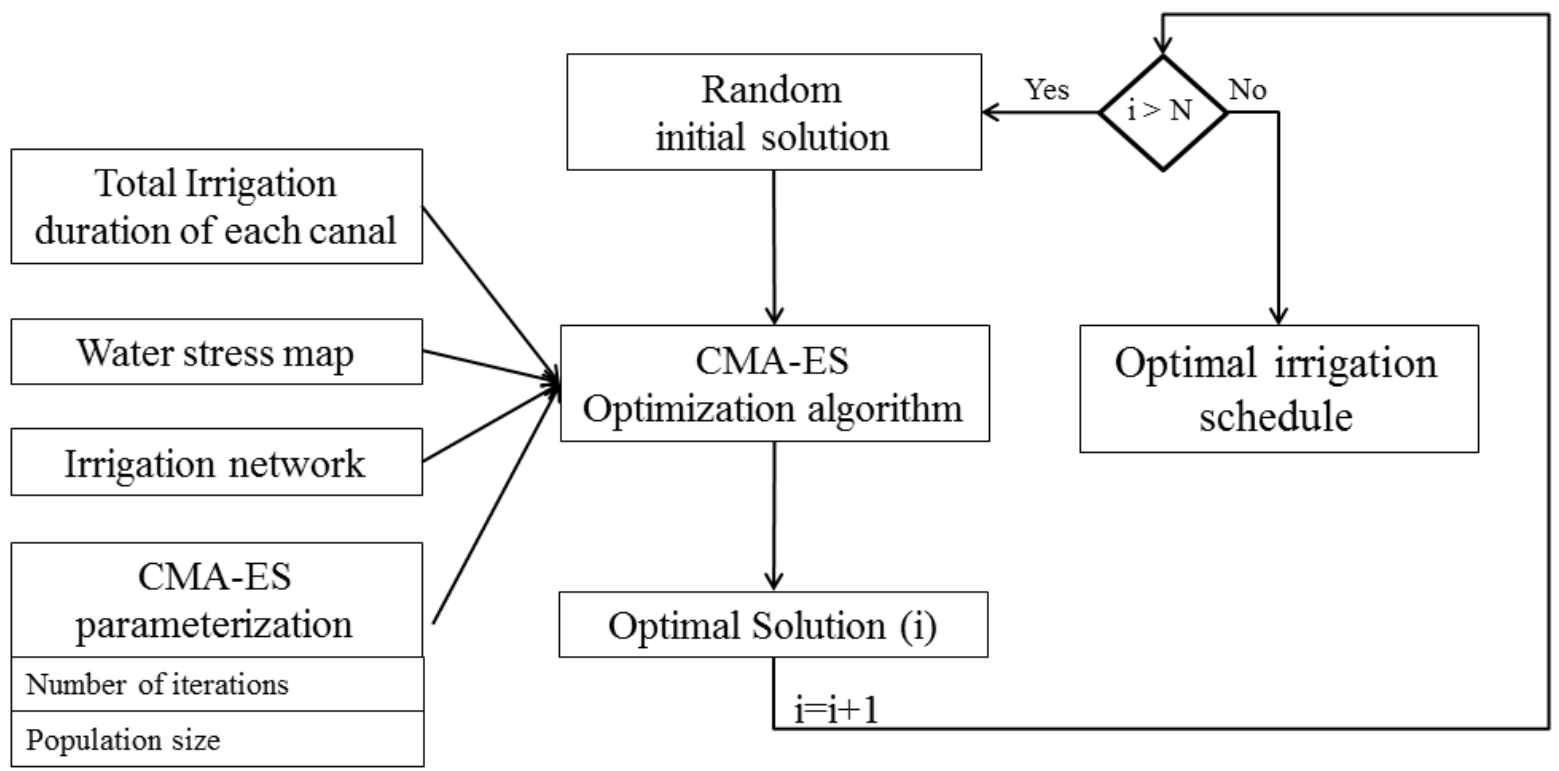


Figure 3

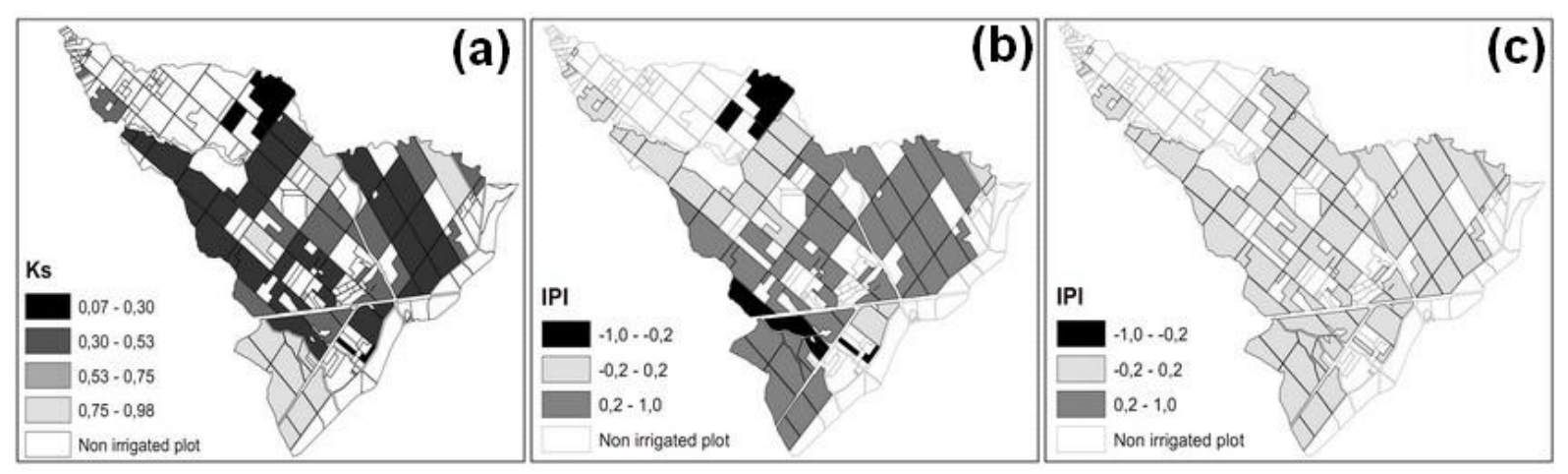


Figure 4
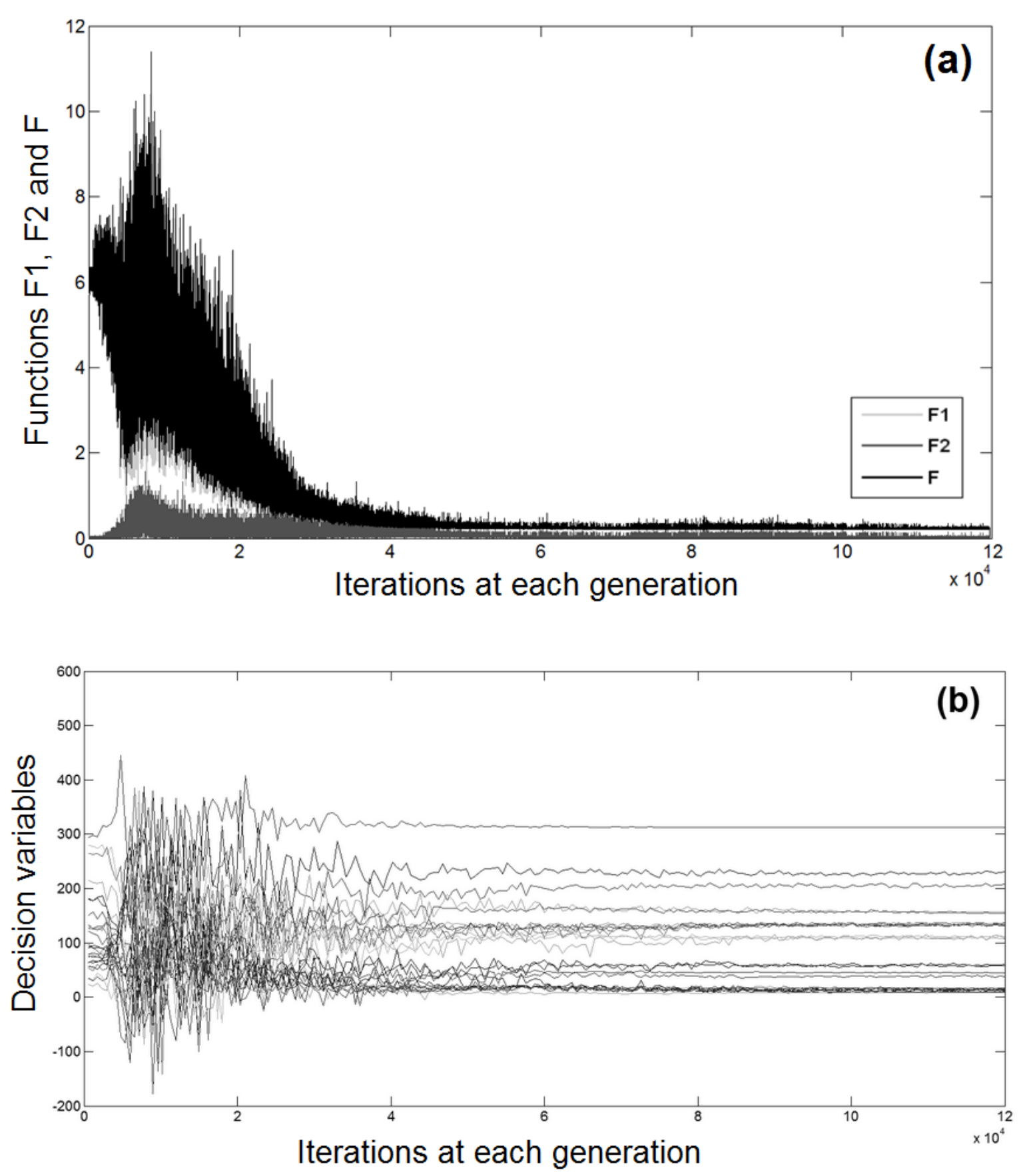


\section{Figure 5}
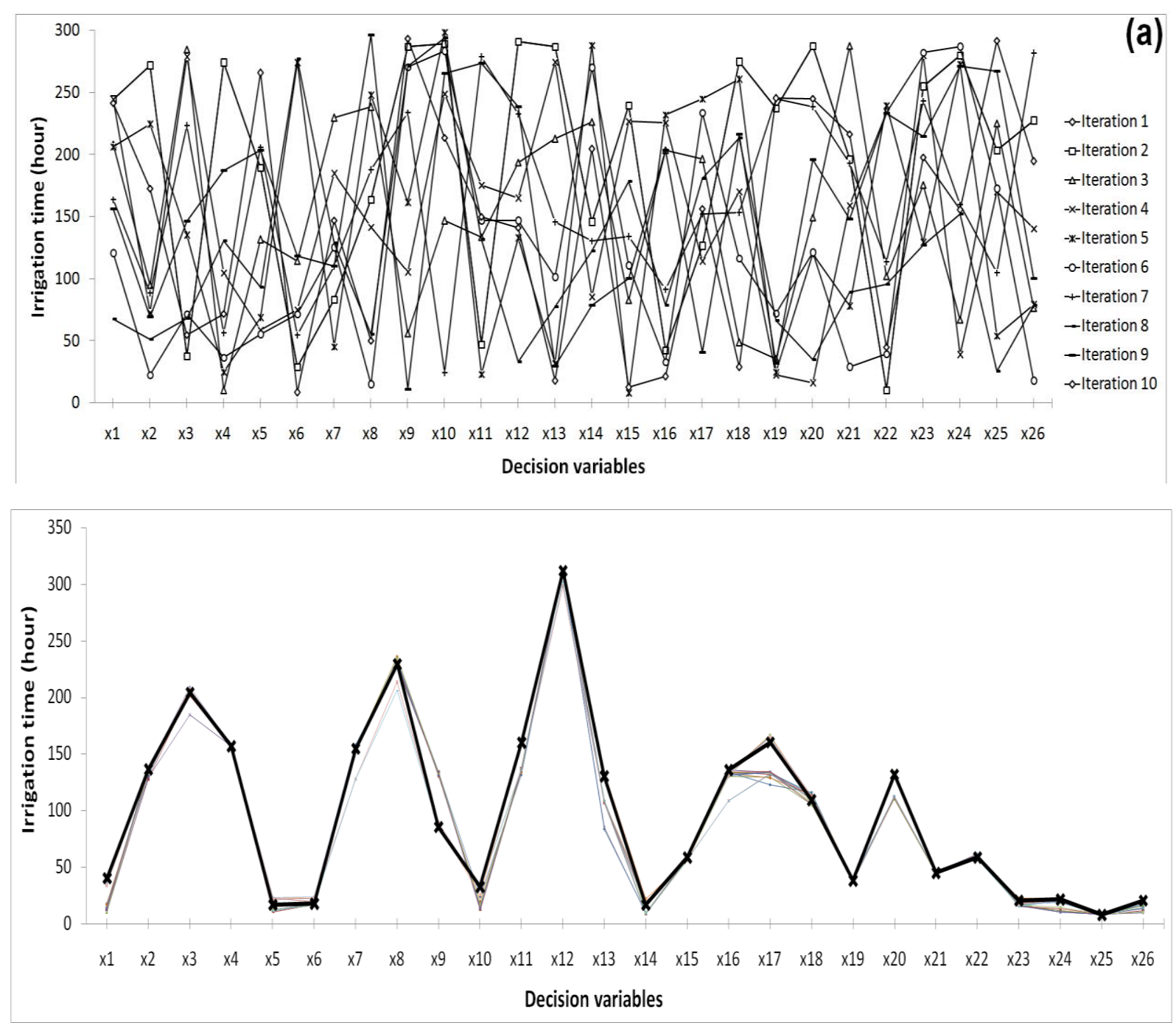

Salwa, il faudrait homogénéiser ces deux figures en (même taille d'abscice pour a et b) (ajouter (b)) et distinguer pour celle du bas les courbes résultant des conditions initiales aléatoires (en gris plein) et celles résultant des perturbations de $K_{\mathrm{S}}$ (en tirets gris). 
Figure 6
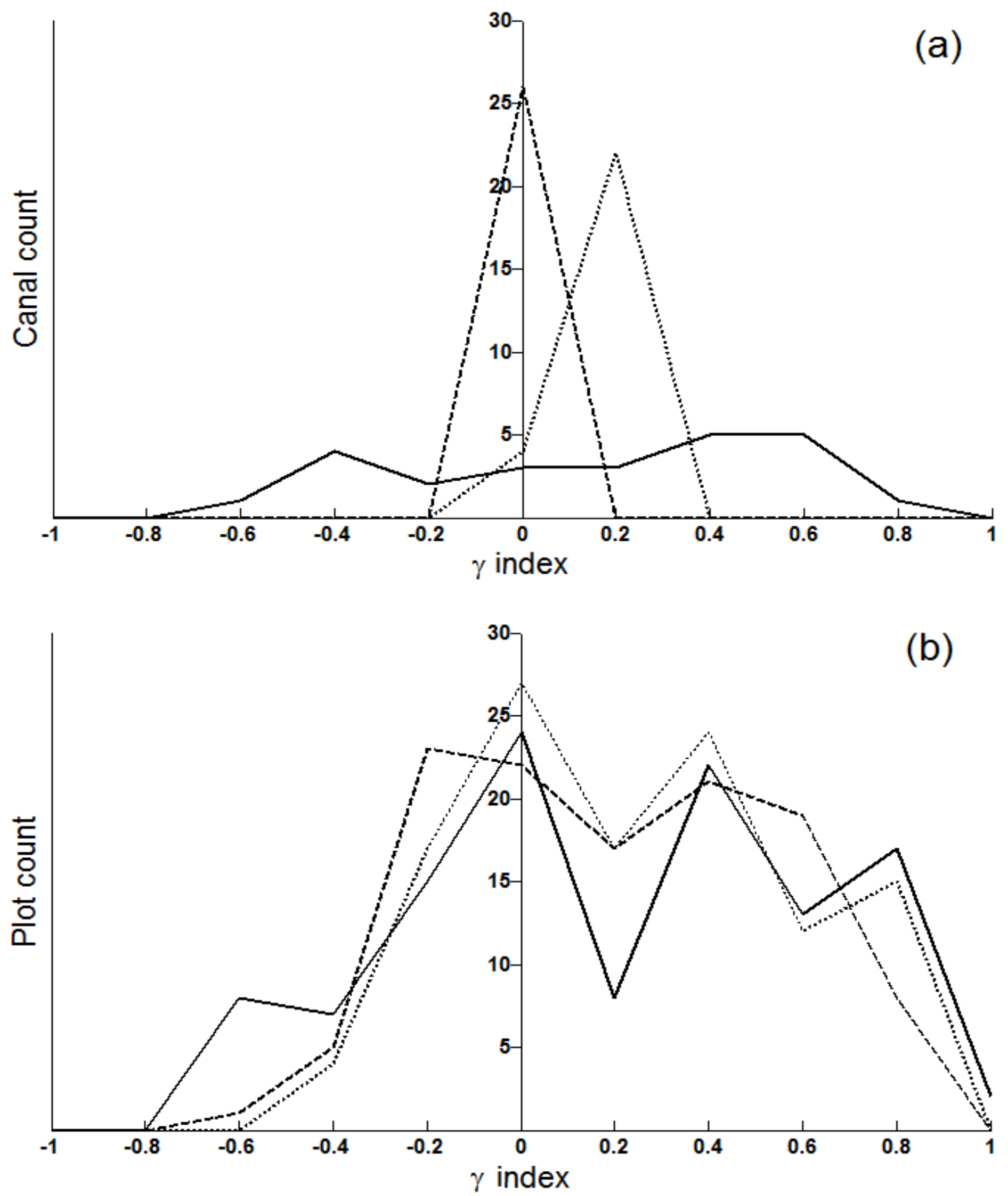
Figure 7

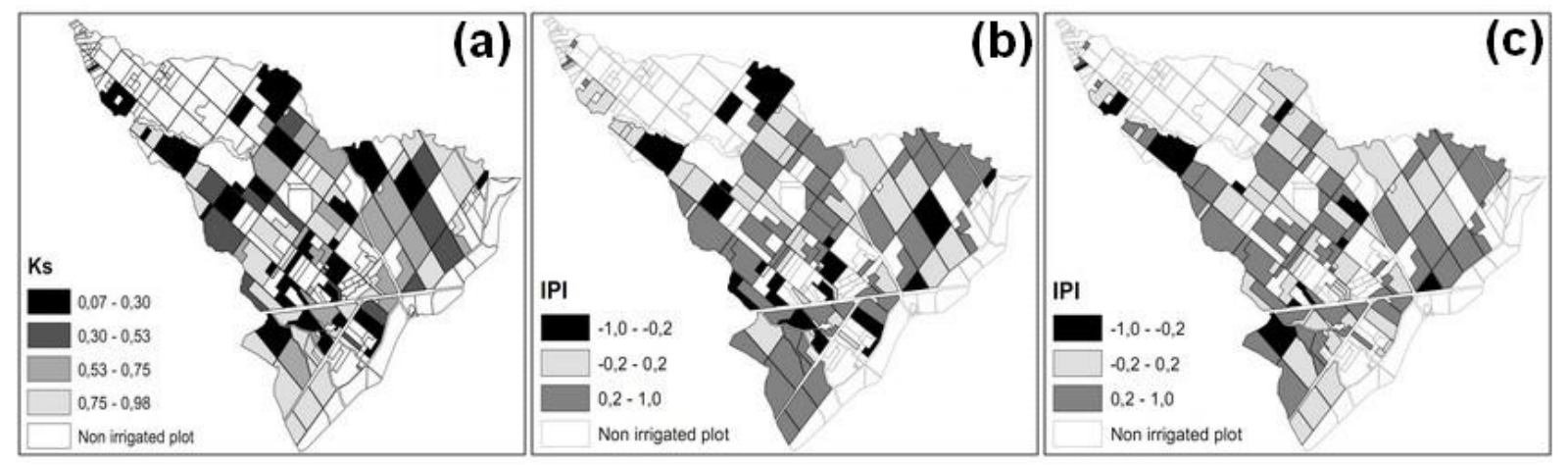




\section{Figure 8}

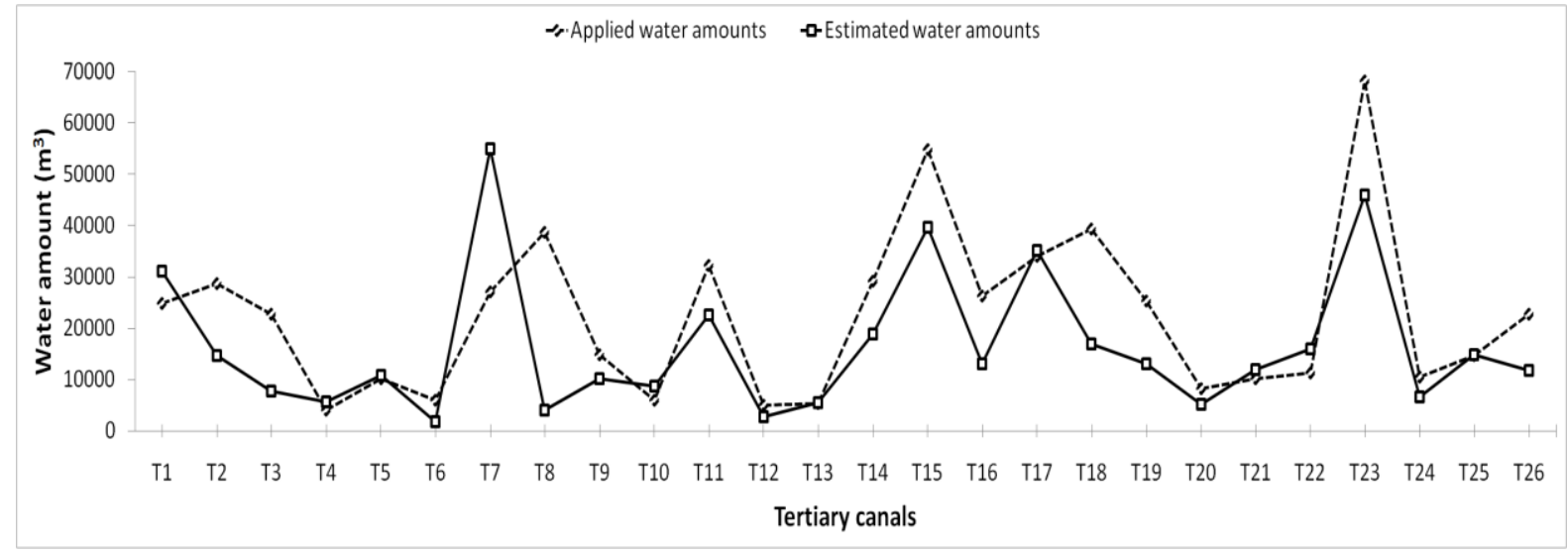

